\title{
Implementation of a Novel Control Technique in Landsman Converter Using Bumble Bee Optimization
}

\author{
Riyaz A. Rahiman ${ }^{1 *}$, M.C. John Wiselin ${ }^{2}$ \\ ${ }^{1}$ Research Scholar, Department of EEE, Bharath University, Chennai. \\ ${ }^{2}$ Research Supervisor, Department of EEE, Bharath University, Chennai.
}

\begin{abstract}
This paper focuses on a solar PV array based BLDC motor employing Landsman converter under partial shading condition (PSC). A converter acts as an interface between the SPV array under PSC and Voltage Source Inverter (VSI) feeding the Brushless DC (BLDC) motor. BLDC motor incorporating the merits of higher efficiency, high reliability, high ruggedness, easy-to-drive, capability to operate successfully at low voltage and excellent performance over a wide range of speed. The speed control of BLDC motor by variable DClink voltage. This eliminates the additional phase current sensing, DC-link voltage sensing, additional control and associated circuitry. The proposed system includes simplicity control, compactness, and soft starting of the BLDC motor. The operation of Landsman converter in CCM results reduced stress on devices. To optimize the operating point of the SPV array in order to get maximum possible power output by means of the better maximum power point tracking (MPPT) technique. The technique is Bumble Bee Mating Optimization (BBMO) based MPPT. The novel technique is compared to the conventional techniques. The simulated results are executed in MATLAB/SIMULINK.
\end{abstract}

\section{Introduction}

Renewable energy resources have enormous potential and offer many advantages over conventional energy resources. Renewable energy comes from several resources like solar, wind, geothermal, biomass and water. They can produce electricity in large quantities over a long term without too emit greenhouse gases. The renewable sources of energy derived from the sun can be used both directly and indirectly. The direct use of solar energy by means of sensors is related to two distinct technologies: the first produces calories, it's solar thermal energy, and the second produces electricity through the photovoltaic effect [Ulliboina Suribabu, 2017]. Photovoltaic (PV) technology is one of the most promising renewable energy technologies. Photovoltaic systems are configured as stand-alone, grid-connected and hybrid systems [Mellit et al., 2009; Fatih Bayrak, 2017]. The photovoltaic energy is a clean energy, with a long lifespan and a high reliability. So, it can be considered as one of the most sustainable renewable energy [Bhim Singh, 2009; Okan Bingöl,2018].

An INC-MPPT technique is applied to track the optimum operating point of SPV array. This technique states that the power slope of the PV array is null, positive and negative, respectively. To implement the INC-MPPT algorithm [Alivarani Mohapatra, 2017], the direct duty ratio control is adapted in view of the simplicity. This method obviating the proportional-integral (PI) controller, directly uses duty ratio as the control parameter. The direct duty ratio perturbation offers very good stability characteristics and high energy utilization efficiency due to the low impact of noise and the absence of oscillation. Moreover, higher perturbation rates up to the PWM rate can be used without losing the global stability of the system. An excellent tracking performance under dynamic condition with negligible oscillations around optimum operating point is achieved [T.R. Premila, 2017].
In conventional DC-DC voltage converters [Ramesh. P, 2017] leads to of heavy voltage ripples at output. In order to control this, ripple conventional carried out these methods used are Equivalent Series Resistant (ESR) Capacitor, adding an inductancecapacitance (LC) filter although these methods have poor transient but difficult to achieve Continuous Conduction Mode (CCM) Some control techniques for DC-DC converter are voltage control techniques, sliding mode converter and loop bandwidth control for the reduction of output voltage ripples. Solar photovoltaic array fed water pump driven and Trajectory Control Using Particle Swarm Optimization are described by [Sethuramalingam, 2016]. Brushless DC motor (BLDCM) is privileged in low power appliances among several available electrical motors. It is preferred due to its high energy density, high efficiency, ruggedness, wide speed range and low maintenance requirement [C.L. Xia, 2012; C.S. Joice et al., 2013; H.A. Toliyat]. Transportation, heating, ventilation and air conditioning (HVAC), medical equipments and several others are major application areas for this motor [Y.T. Chen, 2013; N.Mohan, 2003]. A voltage source inverter (VSI) is used for the electronic commutation of BLDCM based on rotor position sensed by hall-effect position sensors [Y.T. Chen, 2013]. Therefore, inherent issues with brushes and mechanical commutator assembly like as sparking, EMI, wear and tear are eliminated.

Bumble Bees Mating Optimization (BBMO) algorithm is a relatively new swarm intelligence algorithm that simulates the mating behavior that a swarm of bumble bees performs. In this paper, an improved version of the BBMO algorithm is presented for successfully solving the Open Vehicle Routing Problem. The main contribution of the paper is that the equation which describes the movement of the drones outside the hive has been replaced by a local search procedure. Thus, the algorithm became more suitable for combinatorial optimization problems [YannisMarinakis, 2014]. This paper utilizes a relatively new bee's inspired optimization algorithm, the bumble bees mating 
optimization algorithm, to implement a feature subset selection procedure while the nearest neighbor classification method is used for the classification task [Magdalene Marinaki, 2016]. The Bumble Bees Mating Optimization (BBMO) algorithm, is presented in this paper for solving global unconstrained optimization problems. The performance of the algorithm is compared with other popular metaheuristic and nature inspired methods when applied to the most classic global unconstrained optimization problems [Yannis Marinakis, 2010].

In this Solar PV array under partial shading condition based landsman converter fed VSI based BLDC motor. Here the section 2 explaining the partial shading of the solar array. The converter configurations are explained in section 3 and section 4 describes the proposed techniques and the corresponding outputs are discussed in section 5 .

\section{Partial Shading of Solar Panel:}

Shading on solar panels is bad news. In sunlight, each solar cell in an array acts as a little electron pump, pushing electrons from one side of the cell to the other, and giving a voltage boost to the system as they do so. A single cell isn't very powerful though, so in order to get a useful voltage, you need to put quite a number of cells in series. The output of one cell becomes the input to the next cell.

When a cell is shaded, the number of electrons it can pump from one side to the other drops. The shaded solar cell is shown in Fig.1 (a). That, in it, wouldn't be too bad you might think - you would just lose out by the power output of one cell. But unfortunately, because it is not pumping so many electrons up to its neighbor now, it limits the number of electrons that the neighbor can pump too. Same for the next cell in the line and the next, and so on. The other cells can manage to force some extra electrons through the badly performing cell, so it's not quite the case that the whole system performs as poorly as the worst-performing cell in the string - but it's not all that far off. You might easily see a 50\% loss in power from a string of solar cells if just a single cell is shaded. Fortunately, we can help to some extent by fitting bypass diodes to solar panels. Bypass diodes are fitted in parallel with a string of PV cells, and they do exactly what they say on the tin - they allow current to bypass a poorly performing set of cells.

By-pass diodes come into play as shown in the fig. 1 (b). Now, if one panel is shaded, the current produced by the unshaded panel can flow through a by-pass diode to avoid the high resistance of the shaded panel. By-pass diodes will not be of use unless panels are connected in series to produce a higher voltage. They are most likely to be of benefit where an MPPT Controller or String Inverter involves panels connected in series to produce voltages well above that items minimum input voltage. Some solar panels are constructed with the cells divided into groups, each group having a built-in by-pass diode. Shading of part of a panel may be caused by a tree branch, debris, or snow. So, in P-V curve we do not get a unique maximum power point (MPP) but receive several local peaks and one MPP. The P-V curve shown in Fig. 1(c) depicts the multiple maxima during partial shading condition.

String of Solar Cells

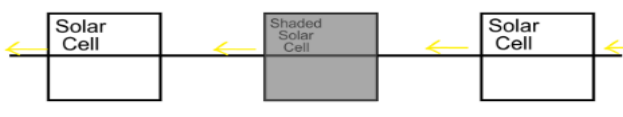

Electrical

(a)

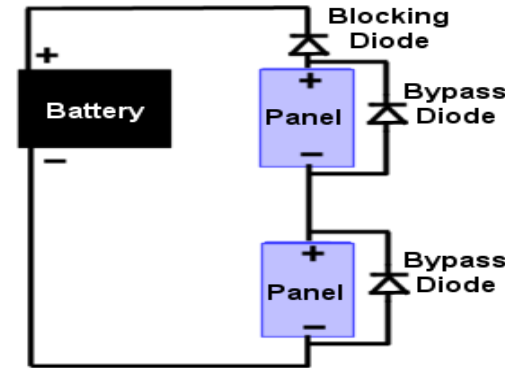

(b)

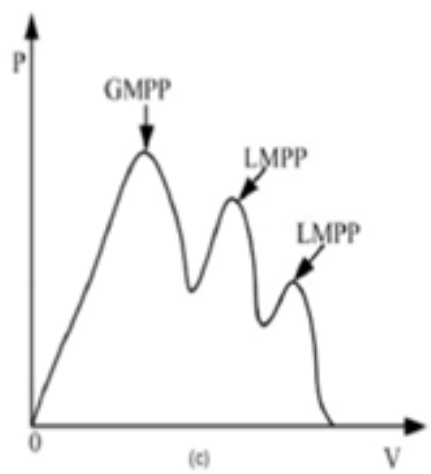

(c)

Fig. 1. (a) Partially shaded solar cell, (b) Bypass diode connected in parallel with the Solar cell, (c) the P-V peaks consisting of GMPP and LMPPs.

\section{Proposed BLDC Motor with VSI Based Landsman Converter:}

\section{Proposed Converter Topology}

The proposed converter is a landsman converter. It is a type of DC-DC converter. The landsman converter circuit diagram is shown in Fig.2 (a). The circuit diagram consists of capacitor $\mathrm{C}_{1}$ and $\mathrm{C}_{2}$, inductor $\mathrm{L}_{1}$ and $\mathrm{L}_{2}$, reversed bias diode and the MOSFET switch. The switching pulse is given from the MPPT controllers. Here we use Bumble Bee mating Optimization (BBMO) based MPPT algorithm is used to provide the suitable switching signal to the converter switch.

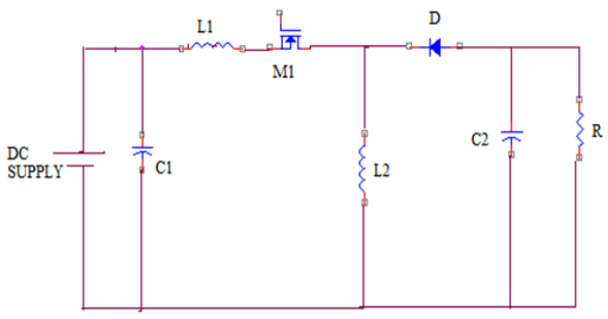

(a)
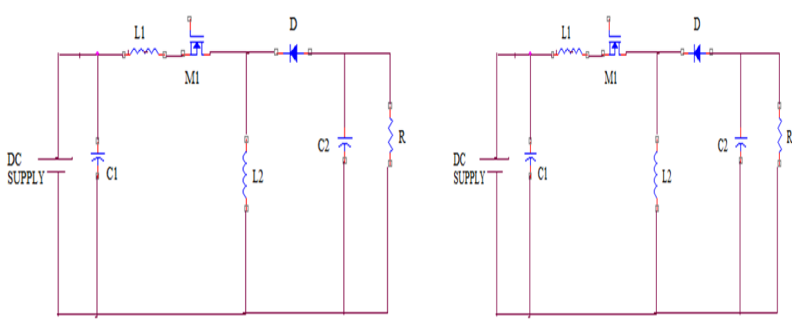

(b)

(c) 


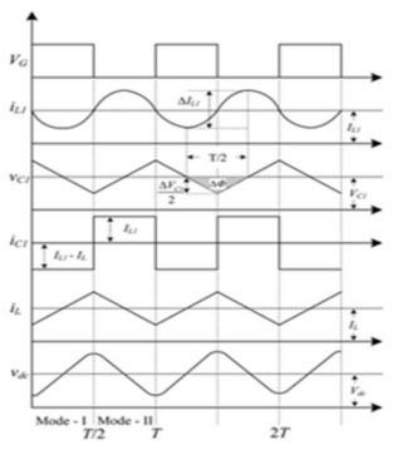

(d)

Fig. 2: (a) proposed converter, (b) the switch is in ON condition, (c) the switch is in OFF condition, (d) the current and voltage waveform

The landsman converter switches reduces the ripple of the output voltage. It works on continuous conduction mode (CCM) and produces a good transient response. Under the Light loading conditions the converter achieving high efficiency and good regulation. So this converter is better compared to the other converter

\section{Working of Landsman Converter}

When Switch is ON: When the switch is in on condition the voltage across the capacitor $\mathrm{C}_{1}$ is $\mathrm{V}_{\mathrm{C}}$, which is greater than the output voltage $\mathrm{V}_{\mathrm{dc}}$. The capacitor $\mathrm{C}_{1}$ is discharges through the switch to transfer the energy to the inductor $\mathrm{L}_{1}$ and the load. The input energy is stored in the inductor $\mathrm{L}_{1}$. Therefore from the resulting waveform the current flow through the inductor is increases and the voltage across the capacitor is decreases. The Switch ON condition circuit diagram is shown in Fig.2 (b) and the corresponding waveform is show in Fig. 2(d).

When switch is OFF: When the switch is in OFF condition, the inductor current flows through the diode and the diode is now forward biased. The capacitor $\mathrm{C} 1$ is charged from the input and the inductor L1. At this time the inductor transfer the energy to the load through the diode. Therefore from the resulting waveform the current flow though the inductor is decreases and the voltage across the capacitor is increases. The Switch OFF condition circuit diagram is shown in Fig.2 (c) and the corresponding waveform is show in Fig. 2(d).

\section{Voltage Source Inverter Fed BLDC Motor}

The converter output is fixed DC voltage. The output of the converter is fed to the inverter. Here voltage source inverter (VSI) is used. The VSI converts the DC voltage to AC voltage. A variable DC bus voltage of the VSI directly controls the speed of the BLDC motor and to reduce the switching losses of the six insulated gate bipolar transistor's (IGBT's) of VSI. A voltage source inverter (VSI) is used for electronic commutation of BLDC motor based on rotor position sensor, which is sensed by Halleffect position sensors. The main circuit diagram is shown in Fig.3. The BLDC motor output is used for various drive applications.

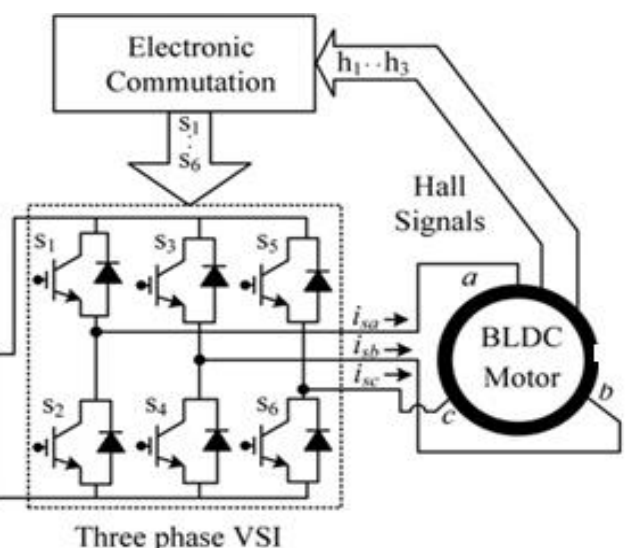

Three phase VSI

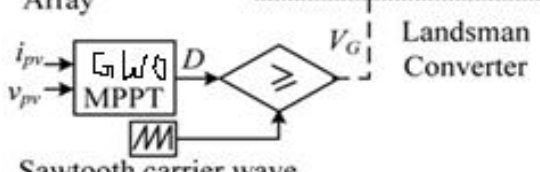

Sawtooth carrier wave

Fig. 3: Schematic representation of landsman converter fed inverter based BLDC motor drive

\section{A Proposed BBMO Based MPPT Algorithm:}

In this paper, a new algorithm that simulates the mating behavior of the Bumble bees, the Bumble Bees Mating Optimization (BBMO) algorithm is presented, analyzed and used for solving unconstrained optimization problems. This algorithm is a population-based swarm intelligence algorithm that simulates the mating behavior that a swarm of bumble bees perform.

In the Bumble Bees Mating Optimization for the MPPT algorithm, there are three kinds of bumble bees in the colony, the queen, many workers (females) and the drones (males). Queens are the only members of the nest to survive from one season to the next, as they spend the winter months hibernating in a protected underground overwintering chamber. Upon emerging from hibernation, a queen collects pollen and nectar from flowers and searches for a suitable nest site and when she finds such a place, she prepares wax pots to store food and wax cells into which eggs are laid. The bumble bee queen can lay fertilized or unfertilized eggs.

A BBMO algorithm has the following steps:

Initialization: Random selection of the initial population of bumble bees

and calculation of their fitness function.

- Drones' Selection: The drones for mating are selected by the queen.

- Offspring' Creation: Three kinds of bumble bees, the new queens (using multi parent crossover), the workers (using multi parent crossover) and the drones (using a mutation operator) are created

- Feeding the new queens: The feeding procedure is used for improving the solutions of the broods in order the fittest of them to become new queens. All the others will become workers.

The equations that show if the new queen decides to be fed from a worker or the old queen are the following: 


$$
L_{1}=\left(u_{\text {bound }}-l_{\text {bound }}\right) \times\left(\omega_{1}-\frac{\omega_{1}}{\text { iter }_{\max }} \times t\right)+l_{\text {bound }}
$$

And

$L_{2}=\left(u_{\text {bound }}-l_{\text {bound }}\right) \times\left(\omega_{2}-\frac{\omega_{2}}{2 * i t e r_{\max }} \times t\right)+l_{\text {bound }}$

Where $t$ is the current iteration, $i_{\text {termax }}$ is the maximum number of iterations and $\mathrm{u}_{\text {bound }}$ and $\mathrm{l}_{\text {bound }}$ are the upper and lower bounds. The parameters $\omega_{1}$ and $\omega_{2}$ control the range of the values L1 and L2. Value L2 should be larger than the value of L1 and, thus, the value of $\omega_{2}$ should be larger than the value of $\omega_{1}$.

The feeding selection is realized from the following equation:

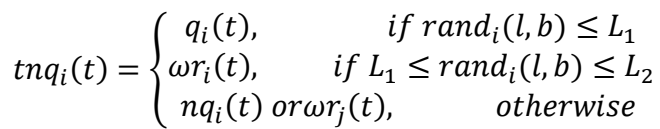

where $t_{n q}$ is the possible new queen (if it has better solution), $q$ is the old queen bee, nq is a brood candidate for new queen and $\omega r_{i}$ and $\omega r_{j}$ are two different workers.
- Mutation phase: In the following the new queens leave from the hive.

Mating phase: The number of the drones per colony in each external generation is:

number of drones per colony $=\frac{\text { number of drones }}{\text { number of queens }}$

The drones, then, leave from the hive and they are looking for new queens for mating.

- Next Iteration: Only the best fertilized queens survive for the next iteration.

\section{Simulation and Discussion}

The MATLAB software was also applied to verify the feasibility of the proposed landsman converter with BBMO based MPPT. The converter is fed to the VSI based BLDC motor drive. Fig.4. illustrates the simulation diagram of the proposed converter under partial shading condition.

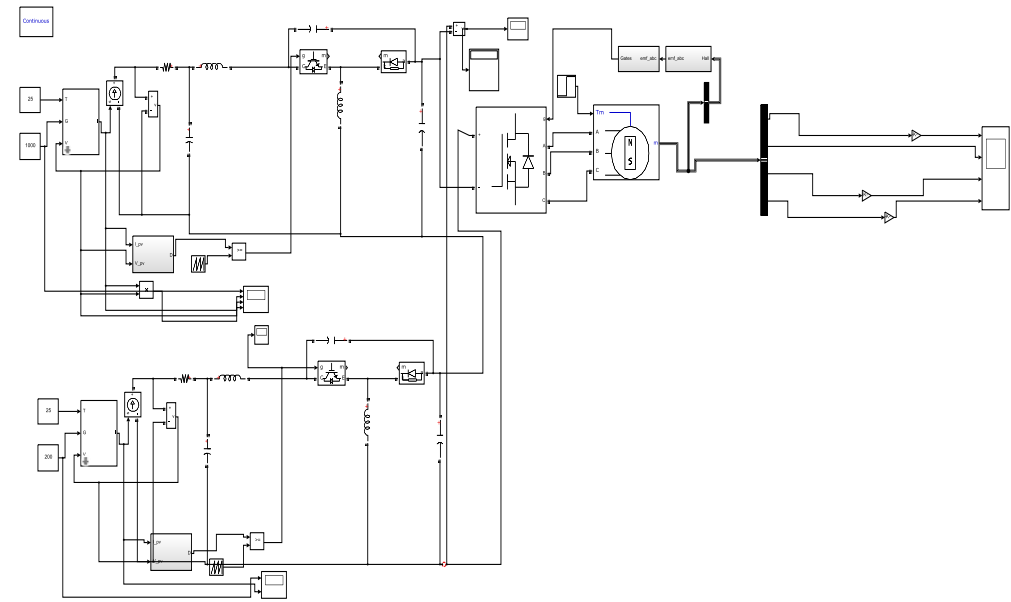

The simulation diagram consists of solar PV array under partial shading condition, landsman converter, VSI and BLDC motor. First the converter is designed to operate in uniform shading conditions. In uniform shading condition the converter is designed to operate in efficient. Then it is apply to the partial shading condition, here the converter output is varied from the uniform shading condition output. So we have to use new optimization techniques to track the maximum power the PV panel. Here we use bumble bee mating based MPPT optimization is used. The partial shading condition simulation diagram is shown in Fig.4.The corresponding simulation results are shown in the below figures.

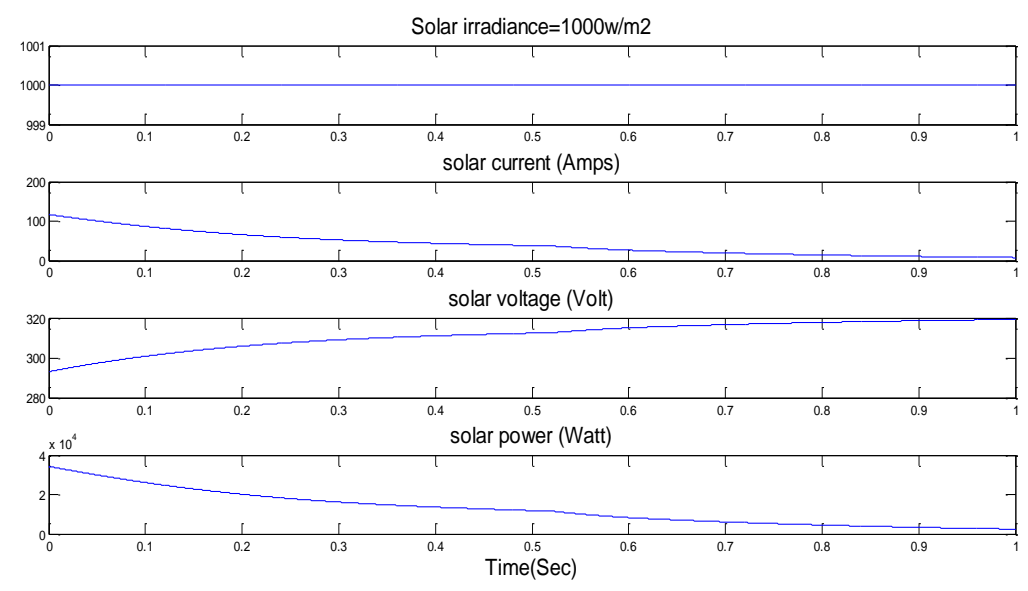

Fig. 4: Simulation results of PV panel Outputs

The PV panel output consists of PV current, voltage, power and irradiance. The PV panel current is $11.2 \mathrm{~A}$, PV voltage is 140 voltage under uniform shading condition, PV power is $2438 \mathrm{~W}$ and the irradiance is $1000 \mathrm{w} / \mathrm{m}^{2}$. The PV panel Output is shown in Fig.4. 


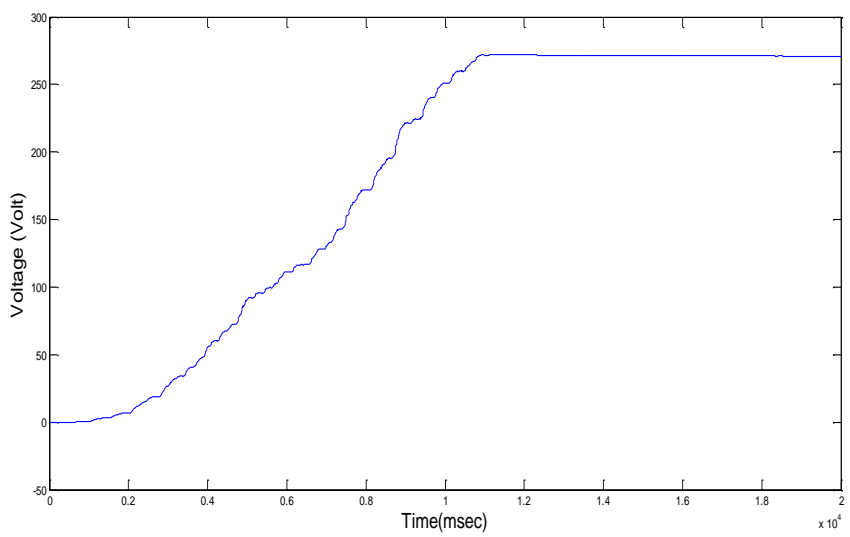

Fig. 5: Proposed converter output voltage

Fig.5. shows the proposed landsman converter output voltage based Solar PV array under partial shading condition. The figure is drawn between Voltage Vs time. The input voltage is taken from the PV panel and the output of the proposed converter is given to the VSI fed BLDC motor. The Input voltage is $140 \mathrm{~V}$. The
PV panel under partial shading condition splits the PV panel into two parts. The first PV parts gives the output voltage is $70 \mathrm{~V}$ and the other PV parts gives another $70 \mathrm{~V}$ voltage to the converter. Therefore the combined input of the converter to produce the output voltage is $290 \mathrm{~V}$.
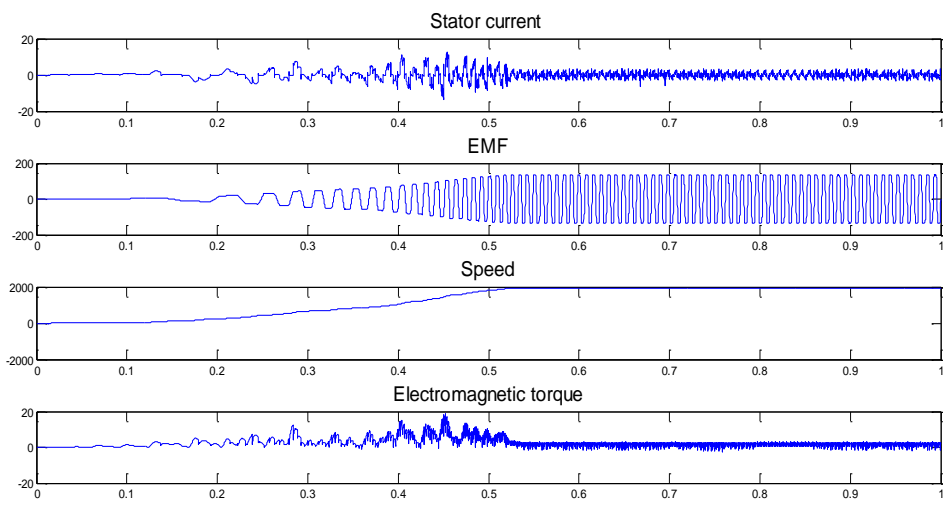

Fig. 6: Simulation results of the landsman converter fed VSI with BLDC motor under partial shading condition

The landsman converter fed VSI with BLDC motor under partial shading condition is shown in Fig.6. The output of the BLDC motor drive is used for various driving applications like pump etc [19]. The BLDC motor outputs are stator current, back EMF, rotor speed and Electromagnetic torque. The values are stator current is $1.22 \mathrm{~A}$, back emf is 132.4 , rotor speed is $1911 \mathrm{rpm}$ and the electromagnetic torque is 0.91 .
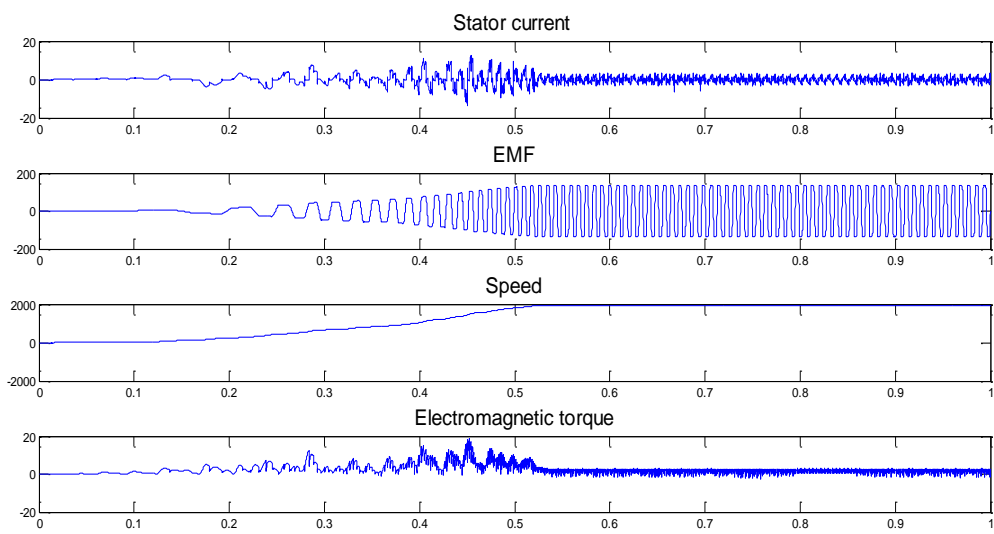

Fig. 7: Simulation results of the proposed Landsman converter with BBMO based MPPT algorithm

Fig.7. shows the simulation results of using optimization technique in the proposed converter. In this reduces the torque content compared to the conventional techniques. The comparison tables with the conventional techniques are shown in the below tables. The motor parameters are compared with conventional techniques are shown in table 1 and the converter time responses are compared with the conventional techniques are shown in table 2.[18] 
Table 1: Comparison for the Performance of BLDC Motor

\begin{tabular}{|l|l|l|l|l|l|}
\hline $\begin{array}{l}\text { Paramete } \\
\text { rs }\end{array}$ & $\begin{array}{l}\text { Converte } \\
\mathrm{r} \text { output } \\
\text { voltage( } \\
\mathrm{V})\end{array}$ & $\begin{array}{l}\text { Stator } \\
\text { current( } \\
\mathrm{A})\end{array}$ & $\begin{array}{l}\text { Back } \\
\text { emf( } \\
\mathrm{V})\end{array}$ & $\begin{array}{l}\text { Rotor } \\
\text { speed(rp } \\
\mathrm{m})\end{array}$ & $\begin{array}{l}\text { Electromagne } \\
\text { tic torque(N- } \\
\mathrm{m})\end{array}$ \\
\hline $\begin{array}{l}\text { Uniform } \\
\text { shading }\end{array}$ & 290.0 & 1.22 & 132 & 1911 & 0.91 \\
\hline $\begin{array}{l}\text { Partial } \\
\text { shading }\end{array}$ & 285.4 & 1.20 & 130.1 & 1865 & 0.94 \\
\hline $\begin{array}{l}\text { Partial } \\
\text { shading } \\
\text { (HBMO- } \\
\text { MPPT) }\end{array}$ & 268.3 & 1.20 & 126.3 & 1868 & 0.95 \\
\hline $\begin{array}{l}\text { Partial } \\
\text { shading } \\
\text { (BBMO- }\end{array}$ & 290 & 1.21 & 131.9 & 1909 & 0.90 \\
MPPT) & & 9 & & \\
\hline
\end{tabular}

Table 2: Comparison of the Converter Time Responses

\begin{tabular}{|l|l|l|}
\hline \multirow{2}{*}{ parameters } & Time responses \\
\cline { 2 - 3 } & Settling time $(\mathrm{m} \mathrm{sec})$ & Rise time $(\mathrm{m} \mathrm{sec})$ \\
\hline $\begin{array}{l}\text { Partial shading } \\
\text { (HBMO-MPPT) }\end{array}$ & 9 & 5 \\
\hline $\begin{array}{l}\text { Partial shading (BBMO- } \\
\text { MPPT) }\end{array}$ & 5 & 3 \\
\hline
\end{tabular}

\section{Conclusion}

A landsman converter fed VSI based BLDC motor under partial shading condition was proposed in this paper. The Partially shaded output is given to the converter. The converter output ripples are reduced by using a new algorithm.ie, bumble bee mating optimization based MPPT. In this track the maximum power from the PV panel. The existing MPPT algorithms are compared with the proposed technique. The operation of Landsman converter in CCM results reduced stress on devices. The proposed technique give the best result compared to the other algorithm based MPPT.

\section{References}

[1] Premila TR, "Solar PV Array Fed BLDC Motor using DC-DC Converter. International Journal of Control Theory and Applications, Vol.10, No. 25, (2017), pp.43-54.

[2] Xia CL, Permanent Magnet Brushless DC motor Drives and controls, Wiles press, Beijing, (2012).

[3] Joice CS, Paranjothi SR \& Kumar, VJS, "Digital control strategy for four quadrant operation of three phase BLDC motor with load variations", IEEE transactions on industrial informatics, Vol.9, No.2, (2013), pp.974-982.

[4] Toliyat HA, DSP-based electromechanical motion control, CRC press, New York, (2004).

[5] Chen YT, "A driver for the single-phase brushless DC fan motor with hybrid winding structure", IEEE Trans. Ind. Electron., Vol.60, No.10, (2013), pp.4369-4375.

[6] Mohan N, Power electronics: converters, Applications and Design, John wiley and sons Inc, USA, (2003).

[7] Sethuramalingam TK \& Nagaraj B, "A Proposed System of Ship Trajectory Control Using Particle Swarm Optimization", Procedia Computer Science, Vol.87, (2016), 294-299.

[8] Ramesh P, "Landsman Converter Based Particle Swarm Optimization Technique", Indonesian Journal of Electrical Engineering and Computer Science, Vol.8, No.2, (2017) pp.619-622.

[9] Mellit A, Kalogirou SA, Hontoria L \& Shaari S, "Artificial intelligence techniques for sizing photovoltaic systems: A review", Renewable and Sustainable Energy Reviews, Vol.13, No.2, (2009), pp.406-419.

[10] Bhim S, "Solar photovoltaic array fed water pump driven by brushless DC motor using Landsman converter", IET Renewable Power Generation, IET Renew. Power Gener., (2009), pp.1-11.
[11] Ulliboina S, "Photovoltaic Based Landsman Converter with Fuzzy Logic Controller Fed BLDC Motor for Water Pumping Applications", International Journal for Modern Trends in Science and Technology, Vol.3, No6, (2017), pp.65-72.

[12] Alivarani M, "A review on MPPT techniques of PV system under partial shading condition", Renewable and Sustainable Energy Reviews, Vol.80, (2017), pp.854-867.

[13] Okan B, "Analysis and comparison of different PV array configurations under partial shading conditions", Solar Energy, Vol.160, (2018), pp.336-343.

[14] Bayrak F, Ertürk G \& Oztop HF, "Effects of partial shading on energy and exergy efficiencies for photovoltaic panels", Journal of cleaner production, vol.164, (2017), pp.58-69.

[15] Yannis M, "A Bumble Bees Mating Optimization algorithm for the Open Vehicle Routing Problem", Swarm and Evolutionary Computation, Vol.15, (2014), pp.80-94

[16] Magdalene M, “A bumble bees mating optimization algorithm for the feature selection problem", International Journal of Machine Learning and Cybernetics, Vol.7, No.4, (2016), pp.519-538.

[17] Yannis M, "A Bumble Bees Mating Optimization Algorithm for Global Unconstrained Optimization Problems", Nature Inspired Cooperative Strategies for Optimization, (2010), pp.305-318.

[18] G, Abikhanova, A Ahmetbekova, E Bayat, A Donbaeva, G Burkitbay (2018). International motifs and plots in the Kazakh epics in China (on the materials of the Kazakh epics in China), Opción, Año 33, No. 85. 20-43.

[19] G Ainabekova, Z Bayanbayeva, B Joldasbekova, A Zhaksylykov (2018). The author in esthetic activity and the functional text (on the basis of V. Mikhaylov's narrative ("The chronicle of the great jute"). Opción, Año 33. 63-80. 